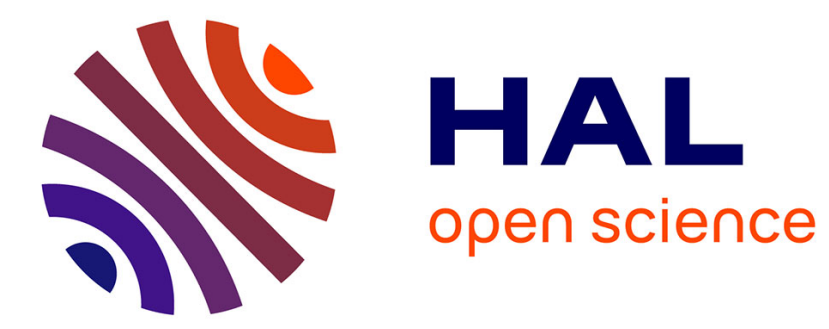

\title{
MRI investigation of internal defects in potato tubers with particular attention to rust spots induced by water stress
}

Ghina Hajjar, Stéphane Quellec, Jérémy Pépin, Sylvain Challois, Gisèle Joly, Carole Deleu, Laurent Leport, Maja Musse

\section{To cite this version:}

Ghina Hajjar, Stéphane Quellec, Jérémy Pépin, Sylvain Challois, Gisèle Joly, et al.. MRI investigation of internal defects in potato tubers with particular attention to rust spots induced by water stress. Postharvest Biology and Technology, 2021, 180, pp.111600. 10.1016/j.postharvbio.2021.111600 . hal03313577

\section{HAL Id: hal-03313577 \\ https: / hal.inrae.fr/hal-03313577}

Submitted on 8 Sep 2021

HAL is a multi-disciplinary open access archive for the deposit and dissemination of scientific research documents, whether they are published or not. The documents may come from teaching and research institutions in France or abroad, or from public or private research centers.
L'archive ouverte pluridisciplinaire HAL, est destinée au dépôt et à la diffusion de documents scientifiques de niveau recherche, publiés ou non, émanant des établissements d'enseignement et de recherche français ou étrangers, des laboratoires publics ou privés. 
MRI investigation of internal defects in potato tubers with particular attention to rust spots induced by water stress

Ghina Hajjar a, Stéphane Quellec a , Jérémy Pépin a, Sylvain Challois a , Gisèle Joly b, Carole Deleu c, Laurent Leport ${ }^{\text {c, }}$ Maja Musse a, ${ }^{\text {* }}$

a UR OPAALE, INRAE, 17 Avenue de Cucillé, CS 64427, 35044 Rennes, France

b Germicopa, 1 allée Loeiz Herrieu 29334 Quimper, France

c UMR IGEPP, INRAE, Institut Agro-Agrocampus Ouest, Université de Rennes 1, Domaine de la Motte, 35653 Le Rheu, France

* Corresponding author: Maja Musse maja.musse@inrae.fr 


\begin{abstract}
Potato quality is a major concern for both producers and customers. However, potato tubers are affected by various forms of internal damage with no external symptoms, leading to substantial economic losses. MRI was used as a non-invasive and quantitative method to evaluate internal defects in potato tubers and their evolution during storage. Rust spots, induced by water stress, were considered in particular. To this end, potato plants were cultivated both in the field and in pots and their water uptake was controlled. Following harvest and throughout the storage period, 3D images of tubers were recorded on a $1.5 \mathrm{~T} \mathrm{MRI}$ scanner using a fast spin echo sequence. In parallel, the multi-exponential transverse relaxation times $\left(T_{2}\right)$ of the tubers were mapped in order to provide information on changes in water status and distribution at the subcellular level in rust spots and in healthy perimedullary regions. The occurrence of rust spots correlated with water conditions in greenhouse where water intake was carefully controlled. The number and individual volume of rust spots did not change during storage period, but they significantly increased with tuber size. Bi-exponential transverse relaxation revealed differences between healthy and damaged tissue.
\end{abstract}

\title{
Keywords
}

Magnetic Resonance Imaging - Rust spots - Internal browning disorder - Tuber Transverse NMR relaxation - Water stress 


\section{Introduction}

Potato (Solanum tuberosum L.) is the world's third most important food crop in terms of human consumption and represents a major source of nutrients including carbohydrates, proteins and vitamins. It is an important staple food grown in over 100 countries around the world. As a crop, the potato is particularly sensitive to drought and heat; it needs a constant water supply throughout its life cycle to achieve high quality yield (Yuan et al., 2003). The impact of drought on the yield and quality of potato tubers is complex: it depends on cultivar, climatic and soil conditions, and water stress timing and duration within the growing period. In general, drought reduces the number and size of tubers, resulting in yield loss (Kang et al., 2004). Drought may also induce physiological disorders that are undetectable before the tuber is cut open such as glassy tubers and internal rust spots (Yencho et al., 2008). These defects are of major concern in the potato industry as they can lead to dissatisfied customers or to the total loss of a crop and its derived food products. In this regard, understanding the impact of water shortages on tuber quality and detecting the occurrence of internal defects have emerged as priority areas for investigation in potato research and production.

The evaluation of internal defects is generally carried out using a destructive method that involves individual grading once potato tubers have been cut in specified locations (Sterrett et al., 1991b). This approach only provides partial information about tuber quality because it is limited to the defects observed in the sections analyzed. Consequently, a number of non-invasive analytical techniques have been developed to enable improvements in defect characterization for potato tubers. Recently, timeresolved reflectance spectroscopy has been proposed as an optical non-destructive method for the detection of rust spots in potato (Ibrahim et al., 2020). This method performed relatively poorly since it correctly identified only those tubers affected by severe rust spots and it required individual calibration for each potato cultivar. A range of imaging techniques have also been used to investigate the quality of potatoes, as discussed in a recent review (Sanchez et al., 2020). Hollow hearts have been detected in potato tubers using X-ray imaging (Finney and Norris, 1978) and infrared hyperspectral imaging (Dacal-Nieto et al., 2011). Similarly, the latter technique has been used for the detection of various defects in potato (Sanchez et al., 2020; Zhang et al., 2019). However, the hyperspectral images obtained in the above studies did not show the detailed structure of the potato tissues. 
Over the past decades, several magnetic resonance imaging (MRI) studies have focused on the characterization of internal disorders. For fruit tissues, MRI has been used to characterize browning (Clark and MacFall, 2003; Defraeye et al., 2013; Finney and Norris, 1978; Musse et al., 2009) and to detect the development of watercore (Herremans et al., 2014). To the best of our knowledge, only a few published works exist on the study of internal browning disorder in potato tubers using MRI (Dacal-Nieto et al., 2011; Thybo et al., 2004). MRI is a non-destructive technique that generally focuses on the imaging of water protons since water is the principal component of most living tissues. Based on longitudinal $\left(T_{1}\right)$ and transverse $\left(T_{2}\right)$ NMR relaxation times, the contrast in MRI images can be adjusted to give a visual image of the internal structure of plant organs. Besides its great potential for the morphological study of fruit and vegetables, MRI is also highly relevant for the evaluation of microstructural changes at the cellular level (Musse et al., 2021; Van As, 2007). In fact, $T_{1}$ and $T_{2}$ of water are sensitive to metabolites content (sugar, starch, etc.), subcellular compartmentation of water and permeability or integrity of cell membrane. In the case of the relatively slow diffusion exchange between compartments, the relaxation signal is multi-exponential due to differences in the physical and chemical properties of the water pools in different compartments (Hills et al., 1990).

MRI studies of defects in fruit and tubers reported in the literature have mainly been performed using $T_{1}$ and/or $T_{2}$ weighted images or mono-exponential relaxation time maps, providing general information about the water status of plant tissues. A large increase in $T_{2}$ was observed in strawberry tissues damaged by a fungal infection (Goodman et al., 1996) and in apple tissues affected with browning (Defraeye et al., 2013; Gonzalez et al., 2001). A decrease in $T_{2}$ was observed in bruised apple tissues arising from membrane damage and the redistribution of intra- and extra-cellular water (McCarthy et al., 1995). For a deeper insight into the microstructural changes in defects, it would be necessary to access water state and distribution at cell compartment level. This requires multi-exponential relaxation time measurements, achieved through MRI optimal signal sampling (Adriaensen et al., 2013).

The aim of the present study was to develop a non-invasive MRI method to identify and characterize internal defects in potato tubers. Emphasis was placed on physiological disorders induced by water stress; namely rust spots detected in the perimedullary region (flesh) of potatoes. Therefore, objectives of this work were first, 
to develop a 3D MRI protocol in order to characterize various defects in the tubers after harvest and to correlate them with the water regimes applied during plant growth, and second, to apply MRI relaxometry for a better understanding of changes happening at subcellular level in rust spots.

\section{Materials and Methods}

\subsection{Experimental trials}

The potato tubers analyzed in this study were harvested from the Rosanna cultivar of Solanum tuberosum potato plants cultivated either in the field or in the greenhouse.

Under field conditions (EARL Lintever, F- 56480 Cleguerec), potato tubers were planted (May $\left.6^{\text {th }}, 2019\right)$ in a deep silted soil from which shoots emerged 1 month later (June $5^{\text {th }}, 2019$ ) and with initiation of tuberization occurring 15 days after shoot emergence (DASE). Two water regimes were applied: (i) rainfed plants receiving 141.5 $\mathrm{mm}$ water rainfall (including $121.0 \mathrm{~mm}$ between 0 and 10 DASE) from shoot emergence to top-kill (62 DASE) and (ii) irrigated plants receiving an additional $70 \mathrm{~mm}$ distributed over 3 dates (31, 39 and 48 DASE). While for the irrigated plants, soil water content remained above critical water-deficit value, for the rainfed plants, soil water content fell below the levels that should be easily available for uptake by plants during the 3 weeks following tuber set (i.e., from 35 to 62 DASE). Rainfed treatment (designated below as 'non-irrigated') resulted in a $16 \%$ decrease in final tuber yield with a $7.6 \mathrm{t}$ lost per ha compared with irrigated conditions.

Under greenhouse conditions (IGEPP, Le Rheu, France), pre-germinated tubers of similar weight (average $23 \pm 2 \mathrm{mg}$ fresh weight) and with 1 to 2 sprouts were retained for planting (one tuber per pot) in $25 \mathrm{~L}$ plastic pots (Airpot ${ }^{\circledR}, 27 \mathrm{~cm}$ diameter, $50 \mathrm{~cm}$ high) filled with a mixture (Falienor® ref. 992016F1) of sandy loam (40\% v/v) and peat moss $(60 \% \mathrm{v} / \mathrm{v})$ with added clay $\left(40 \mathrm{~kg} \mathrm{~m}^{-3}\right)$ and NPK $\left(0.7 \mathrm{~kg} \mathrm{~m}^{-3}\right.$ PG-MIX 14-16-18) (soil solution: $\mathrm{pH} 5.8 \pm 0.2$ and $\left.\mathrm{Ec}(1 / 1.5) 0.7 \mathrm{mS} \mathrm{cm}^{-1}\right)$. Three water regimes were applied during the tuber filling period (from tuber set at 25 DASE to top-kill at 63 DASE): (i) well-watered with to soil humidity levels equivalent to $70 \%$ of field capacity (control), (ii) severe water deficit with to soil humidity levels equivalent to $20 \%$ of field capacity (SWD) and (iii) variable water deficit during which soil humidity levels were 
equivalent to $20 \%$ of field capacity interspersed with 3 periods of rehydration at 33,46 and 60 DASE (VWD). For all conditions, watering ceased from 63 DASE to final tuber harvest. Water deficit treatments resulted in a loss of $230 \mathrm{~g}$ (SWD) and $167 \mathrm{~g}$ (VWD) per plant compared with control samples corresponding to a $63 \%$ (SWD) and $46 \%$ (VWD) decrease of final tuber yield.

\subsection{Samples}

In the case of plants cultivated in the greenhouse (control, SWD and VWD), a total of 96 potato tubers ( 36,24 and 36 tubers, respectively) were analyzed by MRI by collecting the four or five biggest tubers from each plant (8 plants per treatment). In the case of plants grown in the field, 120 tubers with a size of 55-65 (defined in $\mathrm{mm}$ as the lowest tuber diameter), were selected from the irrigated and non-irrigated parcels and analyzed by MRI. The tubers were harvested in August 2019. Immediately after harvest, tubers were stored for 2 weeks at a temperature between 12 and $15^{\circ} \mathrm{C}$ in a well-ventilated dark room to allow the tubers to dry. Then the temperature was gradually decreased to $5^{\circ} \mathrm{C}$ over a period of 2 months. Once this temperature reached, tubers were stored for a period of 5 months. After the last MRI session 33 weeks after harvest (WAH), potato tubers were cut open in order to associate bright spots in MRI images to defects.

\subsection{MRI acquisition protocols and image processing}

During the storage period, MRI measurements were carried out 8 times over a period of 5 months. Dates of measurement sessions are expressed in WAH. Images of potato tubers were recorded on a 1.5 T MRI scanner (Magnetom Avanto, Siemens, Erlangen, Germany) equipped with a circular polarized head array coil. MRI acquisitions were conducted at the storage temperature $\left(5.0 \pm 1^{\circ} \mathrm{C}\right)$ by using a temperature regulating device installed inside the RF coil. Two different MRI protocols were applied allowing (i) the 3D characterization of internal defects and (ii) the determination of $T_{2}$ in healthy and defective potato tuber tissues.

\subsubsection{Characterization of internal defects in potato tubers}

All potato samples from the greenhouse and field plants were analyzed. 3D $T_{1-}$ weighted images of several tubers in a single box were acquired with a resolution of $0.8 \mathrm{~mm} \times 0.8 \mathrm{~mm} \times 0.8 \mathrm{~mm}$ over approximately $30 \mathrm{~min}$ using a standard 3D fast spin 
echo (FSE) sequence with the following parameters: imaging matrix $210 \times 320$, field of view (FOV) $168 \mathrm{~mm} \times 256 \mathrm{~mm}$, slice thickness $0.8 \mathrm{~mm}$, repetition time (TR) $100 \mathrm{~ms}$, echo time (TE) $28 \mathrm{~ms}$, echo train length (ETL) 35, bandwidth (BW) $200 \mathrm{~Hz} \mathrm{pixel}^{-1}, 3$ averages and $66.7 \%$ interpolation in the slice direction. Six potato tubers were placed on rectangular trays and their positions were marked with a permanent marker to ensure they remained the same for all subsequent measurement sessions. Depending on tuber sizes, 2 or 3 trays were then placed in a box designed to be inserted in the temperature regulating device.

An algorithm to detect rust spots and to determine their volume and spatial position was developed using Scilab. The first step was to identify and distinguish between the potato tubers, as these can appear contiguous in MR images. To achieve this, the Otsu segmentation method (Otsu, 1979) and a watershed technique (Beucher and Meyer, 1993) were employed to obtain masks for the tubers. Individual masks were then used for rust spot segmentation based on contrast between healthy and damaged tissues (Kapur et al., 1985).

\subsubsection{Determination of $T_{2}$ in healthy and defective potato-tuber tissues}

Relaxation time measurements were performed for 9 tubers from VWD condition. Four tubers were selected for further analysis because of the relatively large defects detected in their perimedullary regions. The tubers were placed on a tray in such a way as to make it possible to image multiple defects in a single MRI virtual slice. $T_{2}$ maps were acquired with a resolution of $0.9 \mathrm{~mm} \times 0.9 \mathrm{~mm} \times 5.0 \mathrm{~mm}$ over approximately 50 min using a 2D multi-spin echo (MSE) sequence with the following parameters: imaging matrix 160x160, field of view (FOV) $152 \mathrm{~mm} \times 152 \mathrm{~mm}$, slice thickness $5 \mathrm{~mm}$, TR $10 \mathrm{~s}$, TE $7.4 \mathrm{~ms}$, number of echoes 256, bandwidth (BW) $260 \mathrm{~Hz}$ pixel $^{-1}$ and 2 averages.

Multi-exponential transverse relaxation parameters were estimated for the rust spots and for the neighboring healthy perimedullary regions. Regions of interest (ROIs) of similar sizes were manually traced for both tissue states using ImageJ software. The mean signal from each ROI was computed for all MSE sequence images to generate $T_{2}$-decay curves. Values corresponding to a signal-to-noise ratio lower than 7 were removed from the $T_{2}$ curves before fitting, making it possible to assume zero-mean noise distribution in magnitude-reconstructed images at all echo times. Then, $T_{2}$ 
relaxation signals were fitted according to the Levenberg-Marquardt algorithm using TableCurve software. The optimal number of components to describe the multiexponential model was selected by taking into account the coefficient of determination $\left(R^{2}\right)$ of the fit, the global fitting standard error and errors in all individual parameters. The intensity of individual signal components was expressed as a percentage of the total signal, thereby reflecting water distribution between pools.

\section{Results}

3.1. Effect of growth conditions on weight and size of potato tubers

Water deficiency had a strong impact on the weight of tubers grown in both the greenhouse and the field (Figure 1). The mean weight of the five largest tubers of each greenhouse control plant analyzed by MRI was significantly higher $(p<0.00001$, ANOVA test) than that of tubers cultivated under both sets of stress conditions (VWD and SWD). However, there was no significant difference between the weights of tubers cultivated under VWD and SWD. For the plants cultivated in the field, the weight of tubers from irrigated parcels was significantly higher $(p \approx 0.004)$ than that from nonirrigated parcels (Figure 1). Even though tubers of the same diameter were selected, it appears that water shortage had an impact on the length of the tubers in line with previous results (Obidiegwu et al., 2015).

\subsection{Internal defects detected by MRI}

Internal defects in potato tubers detected by MRI appeared as hypo- or hypersignal regions in the affected tissue. According to their position in the tuber, the defects were assigned to one of two main classificatory groups: (i) defects occurring in peripheral parts of the tuber beneath the periderm, usually in the cortex (Figure 2), (ii) and defects occurring in central parts of the tuber, in either the flesh or the inner medulla, also known as the perimedullary region and the pith, respectively (Figure 3). It should be mentioned that none of the potatoes presented in Figures 2 and 3 showed any external visible impacts or defects.

Figure 2 shows MRI images and photographs of the corresponding slices of tubers with defects in the cortex that appeared as hypersignal (Figure $2 \mathrm{~A} \& 2 \mathrm{~B}$ ) or hyposignal (Figure 2C, 2D \& 2E) spots in 3D MRI images. Note that slices observed on MRI images and photographs do not perfectly fit due to differences in thickness in 
each case $(0.8 \mathrm{~mm}$ and $2 \mathrm{~mm}$, respectively). In general, defects found in the cortex are the result of (i) biotic stresses such as damage caused by insects and infections caused by viruses or bacteria, (ii) external impacts during handling of the tuber, or (iii) extreme chemical or thermal conditions during either harvesting or storage of potato tubers. The defects may induce either cell-wall collapse leading to water penetration of intercellular spaces, cell necrosis, or tissue dehydration. Defects found in specific peripheral locations (eye, stem or bud of the tuber) can be related to common defects observed in potato tubers. For example, in Figure 2B, the vascular ring was marked where there was an eye in the tuber and was observed on MRI as a hypersignal short filament at the interface between the cortex and the perimedullary region. Generally, marking of the vascular ring is caused by a chemical desiccation process during the top-kill phase. In Figure 2D, stem-end rot could be the result of an infection caused by stem injury during harvest. Of the defects detected, that shown in Figure $2 \mathrm{E}$ was the only one not present at the beginning of the storage period, but it appeared lately during storage (at $27 \mathrm{WAH}$ ). Its volume remained constant from this date until the end of storage. This defect, of a type known as ventilation bruising, corresponded to a hard, dehydrated region of the tuber tissue that was probably caused by a ventilation draught in the storage room.

Defects detected in the perimedullary region or in the pith are shown in Figure 3. These corresponded to rust spots (Figure 3A) and brown heart (Figure 3B). Rust spots are known to result from physiological disorders induced by water deficiency. In Figure 3A, the bright areas on the MRI images indicated rust spots formed during tuber growth and corresponded to irregular-shaped brown spots in the perimedullary region of the potato tubers. The brown area in the pith (Figure 3B) appeared during storage (at $23 \mathrm{WAH}$ ) and was observed as a hyposignal region on the MRI images. Its volume increased until the end of storage period, during which time, interestingly, the corresponding tuber lost approximately $25 \%$ of its volume. This defect could be an early stage of hollow heart, a common physiological defect affecting potato pith during warm seasons.

Taking into account the analysis of all samples, it can be deduced that the tubers grown in greenhouse conditions developed more internal defects at both the periphery and the center of the tissue than the tubers grown in the field (Figure 4A). The defects observed in the central areas of tubers grown under both greenhouse and in-field 
conditions were predominantly rust spots. These were found in $19 \%$ of tubers from the greenhouse (Figure $4 \mathrm{~B}$ ) and $2 \%$ of tubers from the field. Note that for in-field cultivation, only one tuber from the irrigated parcels and one from the non-irrigated parcels developed internal rust spots. In the greenhouse, $65 \%$ of defective tubers were grown under VWD conditions (Figure 4B). As mentioned above, brown heart (Figure $3 B$ ), was observed in only one tuber grown in the greenhouse under VWD conditions (Figure 4B).

\subsection{Rust spots}

\subsubsection{Monitoring of number and volume of rust spot in greenhouse tubers}

Of the defects listed above, internal rust spots are the typical physiological disorder induced by water stress. Therefore, in this section, only control and VWD tubers grown in the greenhouse will be considered. Tubers from the greenhouse each developed between 1 and 16 rust spots (Figure $4 \mathrm{C} \&$ Table S1), ranging in volume from 1 to $96 \mathrm{~mm}^{3}$, with $81 \%$ of the rust spots having a volume below $20 \mathrm{~mm}^{3}$ (Figure S1 \& Table S1). Their number and volume mainly remained constant during storage. MRI images of a tuber affected by these defects are shown in Figure 5A for three different chronological points during storage. The volume of the corresponding defects was plotted against storage duration (Figure 5B). The volume of rust spots D1, D2, and D3 remained stable during storage. One exception was observed in the form of a single rust spot (D4 in Figure 5) that appeared during storage (at $23 \mathrm{WAH}$ ) in the pith of one tuber. Its volume increased until $27 \mathrm{WAH}$ and then remained stable until the end of the storage period (Figure 5).

To achieve a better understanding of rust-spot occurrence in tubers from the greenhouse, the number of rust spots per tuber was first plotted against the tuber's weight (Figure 6A). No correlation was observed between the number of internal rust spots and weight for the control tubers, which is likely to be explained by the low number of defective tubers. However, a significant positive correlation $\left(R^{2}=0.67\right.$; $p<0.01$ ) was observed between the number of internal rust spots and the weight of tubers grown under VWD conditions. Second, the volume of the largest internal rust spot per tuber was plotted against the tuber's weight (Figure 6B). The volume of these rust spots was significantly higher in the control tubers than in VWD tubers (MannWhitney $U=0<U(4 ; 9)=1$ at $99 \%$ confidence level), which is probably related to the 
size of the tubers. In addition, no correlation was observed between the volume of the biggest rust spot and weight of the control tubers, or in tubers grown under VWD conditions with a mass less than $40 \mathrm{~g}$. However, a significant and high positive correlation $\left(R^{2}=0.97 ; p<0.015\right)$ between the volume of the biggest rust spot and the weight of the tuber (Table S1) grown under VWD conditions was observed for tubers weighing over $40 \mathrm{~g}$. Third, it was observed that rust spots appeared in the largest tubers (sizes 1, 2 or 3; Table S1) of each plant and that the largest tuber of each plant developed more rust spots than smaller tubers of the same plant (P1 of control plants, $\mathrm{P} 1$ and P3 of VWD plants; Table S1).

\subsubsection{Relaxation parameters in rust spots and in healthy perimedullary regions}

In order to better understand rust spots in terms of microstructural changes, transverse relaxation parameters (multi-exponential transverse relaxation time $T_{2}$ and associated relative signal intensity $I_{0}$ ) were measured in both defective tissues and neighboring healthy perimedullary regions throughout the storage period (Figure 7A). The optimum adjustment was reached with a bi-exponential model for both healthy and defective tissues, meaning that MRI relaxometry enabled, in both cases, the detection of two water pools. At the beginning of the storage period, for the healthy perimedullary region, (i) a first signal component was characterized by a $T_{2}$ (comp1) of $70 \pm 3 \mathrm{~ms}$ and (ii) a second signal component was characterized by a $T_{2}$ (comp2) of $220 \pm 17 \mathrm{~ms}$ (Figures 7B \& 7C). Signal distribution, $I_{0}(\mathrm{comp} 1)$ and $I_{0}$ (comp2) between these two components was $34 \pm 3 \%$ and $66 \pm 3 \%$, respectively. The relaxation parameters in healthy perimedullary tissues remained constant throughout the storage period (Figures 7B \& 7C). For rust spots, at the beginning of the storage period, $T_{2}$ was 137 $\pm 21 \mathrm{~ms}$ for the first signal component and $485 \pm 51 \mathrm{~ms}$ for the second signal component (Figures 7B \& 7C) and signal distribution between water pools was approximately $25 \pm 1 \%$ and $75 \pm 1 \%$, respectively. $T_{2}$ of both components decreased between the $14^{\text {th }}$ and $25^{\text {th }}$ WAH and reached $107 \pm 14$ ms and $398 \pm 27$ ms for the first and second signal components, respectively (Figures 7B \& 7C). The relaxation parameters remained stable after $25^{\text {th }}$ WAH until the end of storage period (Figures 7 B \& 7C).

\section{Discussion}


In this work, MRI was used to detect internal defects in potato tubers. It was possible to scan between 12 and 18 tubers in approximately $30 \mathrm{~min}$ and to distinguish defects of different origins with volumes as low as $1 \mathrm{~mm}^{3}$. Among the detected defects, rust spots were of particular interest since they are known to be induced by water deficiency. Other internal disorders typical of water shortage, such as hollow heart and vitreous tissues, were not observed in any of the samples analyzed in our study.

The cause and genesis of rust spots in potato tubers are still a matter of debate. It has been reported that rust spots may result from several environmental stresses such as high temperatures or lack of suitable soil moisture, especially during the last phase of growing or during harvest (Sterrett et al., 1991b). It was also reported that rust spot occurrence was mainly due to the number of rainfall events rather than the total rainfall amount (Sterrett et al., 1991a). Sterrett and co-workers also associated the occurrence of rust spots with a general imbalance in mineral nutrition (Sterrett et al., 2006). Yencho and co-workers considered the role of calcium (Ca) in particular in rust spot occurrence and commented that increased tuber necrosis was linked to low Ca levels (Yencho et al., 2008). In tissues with low Ca content, rust spot occurrence may be associated with the loss of membrane integrity and increase of oxidative stress due to the decrease of activity in enzymes involved in the scavenging of free radicals produced during drought (Yencho et al., 2008). As reviewed by Yencho and coworkers, $\mathrm{Ca}$ is mainly transported to the leaves via the xylem through transpiratory flux (Yencho et al., 2008). Further, drought induces a stronger decrease in the water potential of leaves compared with tubers, resulting in higher $\mathrm{Ca}$ levels in leaves than in tubers. However, it has been demonstrated that $\mathrm{Ca}$ is delivered to tubers through stolon roots near tubers rather than through the main (basal) root system (Busse and Palta, 2006). Parenchymal cells are particularly sensitive to $\mathrm{Ca}$ deficiency. Consequently, the potato flesh (or perimedullary region), would be more impacted by $\mathrm{Ca}$ deficiency than other tissues of the tuber. This explains why, as observed in the present study, rust spots are frequently formed in the apical perimedullary region of tubers adjacent to the vascular ring.

The image obtained by microscopy of a rust spot in the perimedullary region of a potato tuber (Figure S2) showed that the shape of cells in the defect is identical to that of cells in the healthy perimedullary region. However, lugol staining revealed an absence of starch in the defective cells. The lack of starch in rust spots could be due 
to the association of the latter's occurrence with Ca deficiency (Olsen et al., 1996) in the early stages of tuber filling (Sterrett et al., 1991a). So, loss of membrane integrity and oxidative stress induced by Ca deficiency in tuber tissues at an early stage could cause deregulation of starch synthesis and browning (Eliyahu et al., 2015) in the defective tissue (Yencho et al., 2008) .

Depending on the measurement protocols used in previous time domain (TD) NMR studies, two to four signal components were detected in healthy potato tissues (Goodman et al., 1996; Hansen et al., 2010; Mortensen et al., 2005; Thybo et al., 2003). Hills and Le Floc'h proposed an interpretation of the four-exponential signal based on the results of their TD-NMR study of non-freezing water as follows: (i) water in starch granules $\left(T_{2}(\right.$ comp1 $\left.)=2-4 \mathrm{~ms}\right)$, (ii) water associated with cell walls $\left(T_{2}(\right.$ comp2 $\left.)=10 \mathrm{~ms}\right)$, (iii) and water in cytoplasm and vacuoles, associated with two slow-relaxing dominant components with $T_{2}$ between 100 and $500 \mathrm{~ms}$ (Hills and Le Floc'h, 1994). The MRI protocol used in the present study for $T_{2}$ measurements (TE = $7.4 \mathrm{~ms}$; Figure 7A) did not allow quantification of fast-relaxing components with $T_{2}$ in the order of a few milliseconds. The optimum adjustment of transverse relaxation curves was obtained using a bi-exponential model for the rust spots and for the healthy perimedullary regions, indicating that cell membranes acted, at least to some extent, as barriers to diffusive exchanges of water molecules between cell compartments. In both cases, two water pools with similar relative signal amplitudes were detected, probably corresponding to cytoplasm and vacuole compartments (Hills and Le Floc'h, 1994) or to the vacuoles of two cell populations with distinct volume distributions, as has been observed in peaches (Musse et al., 2021). Both $T_{2}$ s of the bi-exponential relaxation signal were higher in the rust spots than the healthy tissues. This could be explained, at least partially, by changes in the membrane structures. Indeed, in a previous MRI study of potato at 4.7 T, Dacal-Nieto and co-workers also observed an increase in the mono-exponential $T_{2}$ of rust spots and explained this by suggesting that the loss of membrane structures reduced restrictions on the mobility of water molecules and therefore increased $T_{2}$ (Dacal-Nieto et al., 2011). An alternative hypothesis on the cause of the increase in the $T_{2}$ values of both components in rust spots as compared with those of the neighboring healthy perimedullary region would be the lower starch content in the defective tissues, in accordance with our own microscope observations of defective potato tissues (Figure S2) and with NMR results obtained for banana 
(Raffo et al., 2005). The increase in the $T_{2}$ of two water pools attributed to the vacuolar and cytoplasmic compartments as the banana fruit ripened was explained by a degradation of the starch granules (Raffo et al., 2005). Indeed, proton chemical exchanges between water and starch molecules were observed to decrease $T_{2}$ considerably, not only for water in amyloplasts, but also for cytoplasmic and vacuolar water via diffusive exchanges of water between these compartments through the membranes (Raffo et al., 2005). On the other hand, in apple tissues affected by internal browning, higher values for mono-exponential $T_{2}$, proton density, and diffusion coefficient were recorded compared with those of healthy neighboring tissues (Defraeye et al., 2013). The increase in $T_{2}$ was explained by a reduction in magnetic susceptibility effects, produced by cell liquid filling the intercellular air spaces. In the present study, the micrographs (Figure S2) did not show such tissue modifications ant therefore this hypothesis was not retained.

In the present study, the occurrence of rust spots correlated with water conditions in the greenhouse, where water intake was carefully controlled. The greater occurrence of rust spots under VWD conditions (none detected in SWD conditions (data not shown) and only a few in control samples) could be explained by the dilution of $\mathrm{Ca}$ in the growing tubers during periods of intermittent watering. Indeed, a lower $\mathrm{Ca}$ uptake by the lateral stolon rooting systems affected by water shortage was to be expected. Likewise, Raimo and co-workers have shown that the incidence of internal brown spots was influenced by water supply (Raimo et al., 2018). The present study also demonstrates that rust-spot volume correlates with tuber size, again in accordance with Raimo and co-workers (Raimo et al., 2018), who found a positive correlation between incidence and severity of rust spots and potato tuber size using the traditional cutting method. Further, we observed a greater number of rust spots in the largest tuber of each plant. In this study, as in previous work (Raimo et al., 2018; Sterrett et al., 1991b), damaged tissues generally appeared first in the largest tubers. Further, the number and volume of rust spots did not change during potato storage, in line with previous observations of apples (Defraeye et al., 2013), pears (Clark and MacFall, 2003; Finney and Norris, 1978) and potatoes (Ibrahim et al., 2020; Raimo et al., 2018; Sterrett et al., 1991b). A single exception in our study was observed for one rust spot shown in Figure 5. This was probably the consequence of an abnormal expression of this disorder. It was assumed that the rust spots detected in the potato 
tubers occurred at different developmental stages, since we observed, after cutting, that the appearance (color) of rust spots was not the same for all defects. Similarly, on $\mathrm{MRI}$ images, the signal intensity of regions corresponding to rust spots, and thus biexponential $T_{2}$ values, fluctuated between the different defects (data not shown). As a result, the standard deviations for both short and long $T_{2}$ values in rust spots were higher than those for the healthy perimedullary regions (Figures $7 \mathrm{~B} \& \mathrm{C}$ ). On the other hand, bi-exponential $T_{2}$ decreased in rust spots during the first ten weeks of storage differing from observed values in healthy tissues, a fact that also proves that microstructural changes were still ongoing following rust spot formation. Changes in the morphology of defects were also observed during the storage of apples and pears with no effect on the volume of rust spots (Defraeye et al., 2013; Finney and Norris, 1978). In apples, progressive browning induced a heterogeneity in the defective tissue (Clark and MacFall, 2003; Defraeye et al., 2013). In pears, a dehydrated cavity was formed leading to signal loss (Finney and Norris, 1978). It should be mentioned that the origin of internal browning disorder in potatoes seems to be different from that in fruit (apples and pears). In the latter, internal browning disorder is induced by high $\mathrm{CO}_{2}$ concentrations during modified-atmosphere storage (Hills et al., 1990). However, internal rust spots in potato are generally formed during the growth stage of tubers.

The protocol proposed here could be applied for the monitoring of internal defects in other fruit, vegetables and tubers. Minor adjustments of MRI parameters would be required to ensure optimal image contrast and resolution but the MRI protocol is calibration-free, representing an advantage compared with, for example, timeresolved spectroscopy in potato research where calibration is needed for each cultivar (Ibrahim et al., 2020).

\section{Conclusions}

The results presented here allow us to conclude that the MRI protocol was successfully implemented for the detection and characterization of internal damage in potato tubers. Depending on their location in the tuber, detected defects can be classified according to potential origin and their state can be tracked non-destructively over a given period. In the context of climate change and global heating that will affect most areas of potato crop cultivation, the proposed method is useful in providing a detailed characterization of the effects of water stress on potatoes at macrostructural, 
cellular and subcellular levels. The analysis of rust spots described here conforms to existing knowledge of their occurrence and evolution in potato tubers during storage. However, the relaxation measurements performed here have demonstrated that microstructural changes may still be ongoing at the beginning of storage period. To achieve a deeper understanding of the development of rust spots, MRI protocols are currently being tested for the in situ monitoring of the occurrence of rust spots in tubers during growth. 


\section{Appendices}

\section{Acknowledgments}

We are most grateful to the PRISM core facility (Rennes-Angers, France) for its technical support and to the GIS Biogenouest. We would like to thank François Mariette for his participation in research design, Philippe Dolo and Arnaud Barbary from Bretagne Plants Innovation (BPI, Hanvec, France) and Patrick Leconte from IGEPP for providing the field-grown (BPI) and pot-grown (IGEPP) potato tubers analyzed in this study. Thanks also go to Alain Fautrel and Gevorg Ghukasyan from the HistoPathology High-Precision H2P2 platform for their assistance with microscopy.

\section{Funding}

This work is part of the TuberBioScan research project financed by the Brittany region and FEDER as part of the Innovation collaborative au croisement des filières program.

\section{References}

Adriaensen, H., Musse, M., Quellec, S., Vignaud, A., Cambert, M., Mariette, F., 2013. MSE-MRI sequence optimisation for measurement of bi- and tri-exponential T2 relaxation in a phantom and fruit. Magnetic Resonance Imaging 31, 1677-1689. DOI: 10.1016/j.mri.2013.02.004

Beucher, S., Meyer, F., 1993. The Morphological Approach to Segmentation: The Watershed Transformation, Mathematical Morphology in Image Processing. Marcel Dekker Inc., New York.

Busse, J.S., Palta, J.P., 2006. Investigating the in vivo calcium transport path to developing potato tuber using 45Ca: a new concept in potato tuber calcium nutrition. Physiologia Plantarum 128, 313-323. DOI: 10.1111/j.1399-3054.2006.00741.x

Clark, C.J., MacFall, J.S., 2003. Quantitative magnetic resonance imaging of 'Fuyu'persimmon fruit during development and ripening. Magnetic Resonance Imaging 21, 679-685. DOI: 10.1016/s0730-725x(03)00082-1

Dacal-Nieto, A., Formella, A., Carrión, P., Vazquez-Fernandez, E., FernándezDelgado, M., 2011. Non-destructive detection of hollow heart in potatoes using hyperspectral imaging, International Conference on Computer Analysis of Images and Patterns. Springer, pp. 180-187.

Defraeye, T., Lehmann, V., Gross, D., Holat, C., Herremans, E., Verboven, P., Verlinden, B.E., Nicolai, B.M., 2013. Application of MRI for tissue characterisation of 'Braeburn' apple. Postharvest Biology and Technology 75, 96-105. DOI: 10.1016/j.postharvbio.2012.08.009 
Eliyahu, E., Rog, I., Inbal, D., Danon, A., 2015. ACHT4-driven oxidation of APS1 attenuates starch synthesis under low light intensity in Arabidopsis plants. Proceedings of the National Academy of Sciences 112, 12876-12881.

Finney, E., Norris, K., 1978. X-ray scans for detecting hollow heart in potatoes. American Potato Journal 55, 95-105.

Gonzalez, J.J., Valle, R.C., Bobroff, S., Biasi, W.V., Mitcham, E.J., McCarthy, M.J., 2001. Detection and monitoring of internal browning development in 'Fuji'apples using MRI. Postharvest Biology and Technology 22, 179-188.

Goodman, B., Williamson, B., Simpson, E., Chudek, J., Hunter, G., Prior, D., 1996. High field NMR microscopic imaging of cultivated strawberry fruit. Magnetic Resonance Imaging 14, 187-196.

Hansen, C.L., Thybo, A.K., Bertram, H.C., Viereck, N., van den Erg, F., Engelsen, S.B., 2010. Determination of Dry Matter Content in Potato Tubers by Low-Field Nuclear Magnetic Resonance (LF-NMR). Journal of Agricultural and Food Chemistry 58, 10300-10304. DOI: $10.1021 / \mathrm{jf} 101319 q$

Herremans, E., Melado-Herreros, A., Defraeye, T., Verlinden, B., Hertog, M., Verboven, P., Val, J., Fernández-Valle, M.E., Bongaers, E., Estrade, P., Wevers, M., Barreiro, P., Nicolaï, B.M., 2014. Comparison of X-ray CT and MRI of watercore disorder of different apple cultivars. Postharvest Biology and Technology 87, 42-50. DOI: $10.1016 /$ j.postharvbio.2013.08.008

Hills, B., Le Floc'h, G., 1994. NMR studies of non-freezing water in cellular plant tissue. Food Chemistry 51, 331-336.

Hills, B., Takacs, S., Belton, P.S., 1990. A new interpretation of proton NMR relaxation time measurements of water in food. Food Chemistry 37, 95-111.

Ibrahim, A., Grassi, M., Lovati, L., Bruno, P., Spinelli, L., Torricelli, A., Rizzolo, A., Vanoli, M., 2020. Non-destructive detection of potato tubers internal defects: critical insight on the use of time resolved spectroscopy. Advances in Horticultural Science 34, 43-51. DOI: 10.13128/ahsc-7653

Kang, Y.H., Wang, F.X., Liu, H.J., Yuan, B.Z., 2004. Potato evapotranspiration and yield under different drip irrigation regimes. Irrigation Science 23, 133-143.

Kapur, J.N., Sahoo, P.K., Wong, A.K., 1985. A new method for gray-level picture thresholding using the entropy of the histogram. Computer vision, graphics, and image processing 29, 273-285.

McCarthy, M., Zion, B., Chen, P., Ablett, S., Darke, A., Lillford, P., 1995. Diamagnetic susceptibility changes in apple tissue after bruising. Journal of the Science of Food and Agriculture 67, 13-20. DOI: https://doi.org/10.1002/jsfa.2740670103

Mortensen, M., Thybo, A.K., Bertram, H.C., Andersen, H.J., Engelsen, S.B., 2005. Cooking Effects on Water Distribution in Potatoes Using Nuclear Magnetic Resonance Relaxation. Journal of Agricultural and Food Chemistry 53, 5976-5981. DOI: $10.1021 /$ jf0479214

Musse, M., Bidault, K., Quellec, S., Brunel, B., Collewet, G., Cambert, M., Bertin, N., 2021. Spatial and temporal evolution of quantitative magnetic resonance imaging parameters of peach and apple fruit-relationship with biophysical and metabolic traits. The Plant Journal 105, 62-78. DOI: 10.1111/tpj.15039 
Musse, M., Quellec, S., Devaux, M.-F., Cambert, M., Lahaye, M., Mariette, F., 2009. An investigation of the structural aspects of the tomato fruit by means of quantitative nuclear magnetic resonance imaging. Magnetic Resonance Imaging 27, 709-719. DOI: 10.1016/j.mri.2008.11.005

Obidiegwu, J.E., Bryan, G.J., Jones, H.G., Prashar, A., 2015. Coping with drought: stress and adaptive responses in potato and perspectives for improvement. Frontiers in Plant Science 6.DOI: 10.3389/fpls.2015.00542

Olsen, N.L., Hiller, L.K., Mikitzel, L.J., 1996. The dependence of internal brown spot development upon calcium fertility in potato tubers. Potato Research 39, 165-178.

Otsu, N., 1979. A threshold selection method from gray-level histograms. IEEE transactions on systems, man, and cybernetics 9, 62-66.

Raffo, A., Gianferri, R., Barbieri, R., Brosio, E., 2005. Ripening of banana fruit monitored by water relaxation and diffusion $1 \mathrm{H}-\mathrm{NMR}$ measurements. Food Chemistry 89, 149-158. DOI:10.1016/j.foodchem.2004.02.024

Raimo, F., Pentangelo, A., Pane, C., Parisi, B., Mandolino, G., 2018. Relationships Between Internal Brown Spot and Skin Roughness in Potato Tubers Under Field Conditions. Potato Research 61, 327-339. DOI:10.1007/s11540-018-9380-5

Sanchez, P.D.C., Hashim, N., Shamsudin, R., Nor, M.Z.M., 2020. Applications of imaging and spectroscopy techniques for non-destructive quality evaluation of potatoes and sweet potatoes: A review. Trends in Food Science \& Technology 96, 208-221. DOI: 10.1016/j.tifs.2019.12.027

Sterrett, S., Haynes, K., Yencho, G., Henninger, M., Vinyard, B., 2006. 4x-2x potato clones with resistance or susceptibility to internal heat necrosis differ in tuber mineral status. Crop science 46, 1471-1478. DOI: 10.2135/cropsci2005.06-0093

Sterrett, S., Lee, G., Henninger, M., Lentner, M., 1991a. Predictive Model for Onset and Development of Internal Heat Necrosis ofAtlantic'Potato. Journal of the American Society for Horticultural Science 116, 701-705.

Sterrett, S.B., Henninger, M.R., Lee, G.S., 1991b. Relationship of Internal Heat Necrosis of Potato to Time and Temperature after Planting. Journal of the American Society for Horticultural Science 116, 697-700.

Thybo, A.K., Andersen, H.J., Karlsson, A.H., Donstrup, S., Stodkilde-Jorgensen, H., 2003. Low-field NMR relaxation and NMR-imaging as tools in differentiation between potato sample and determination of dry matter content in potatoes. LebensmittelWissenschaft Und-Technologie-Food Science and Technology 36, 315-322. DOI: 10.1016/S0023-6438(02)00210-4

Thybo, A.K., Jespersen, S.N., Laerke, P.E., Stodkilde-Jorgensen, H.J., 2004. Nondestructive detection of internal bruise and spraing disease symptoms in potatoes using magnetic resonance imaging. Magnetic Resonance Imaging 22, 1311-1317. DOI: 10.1016/j.mri.2004.08.022

Van As, H., 2007. Intact plant MRI for the study of cell water relations, membrane permeability, cell-to-cell and long distance water transport. Journal of Experimental Botany 58, 743-756. DOI: 10.1093/jxb/erl157

Yencho, G.C., McCord, P.H., Haynes, K.G., Sterrett, S.R., 2008. Internal heat necrosis of potato-a review. American Journal of Potato Research 85, 69-76. DOl: $10.1007 / \mathrm{s} 12230-008-9008-4$ 
Yuan, B.Z., Nishiyama, S., Kang, Y.H., 2003. Effects of different irrigation regimes on the growth and yield of drip-irrigated potato. Agricultural Water Management 63, 153167.

Zhang, W., Zhu, Q., Huang, M., Guo, Y., Qin, J., 2019. Detection and classification of potato defects using multispectral imaging system based on single shot method. Food Analytical Methods 12, 2920-2929. DOI:10.1007/s12161-019-01654-w 


\section{Figures}

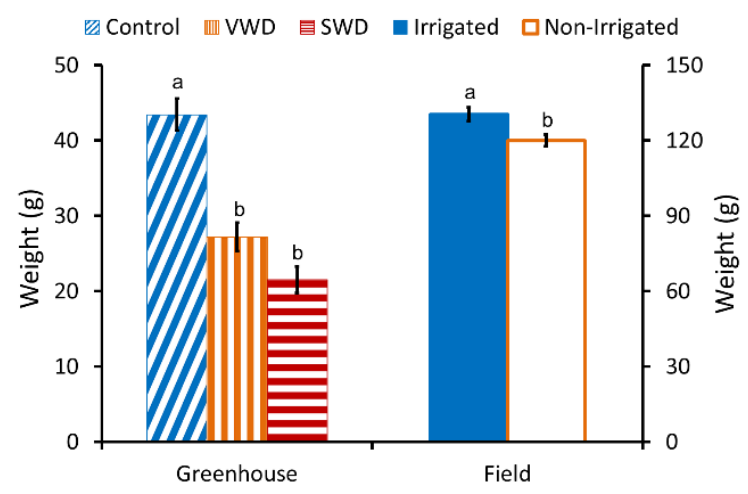

Figure 1: Mean weight of tubers grown: (left axis) in greenhouse under optimal conditions (Control), variable water shortage (VWD) or severe water shortage (SWD) and (right axis) in the field under irrigated and rainfed (non-irrigated) water regimes. For each set of conditions, values marked with different letters are significantly different at a $99 \%$ confidence level (ANOVA). 

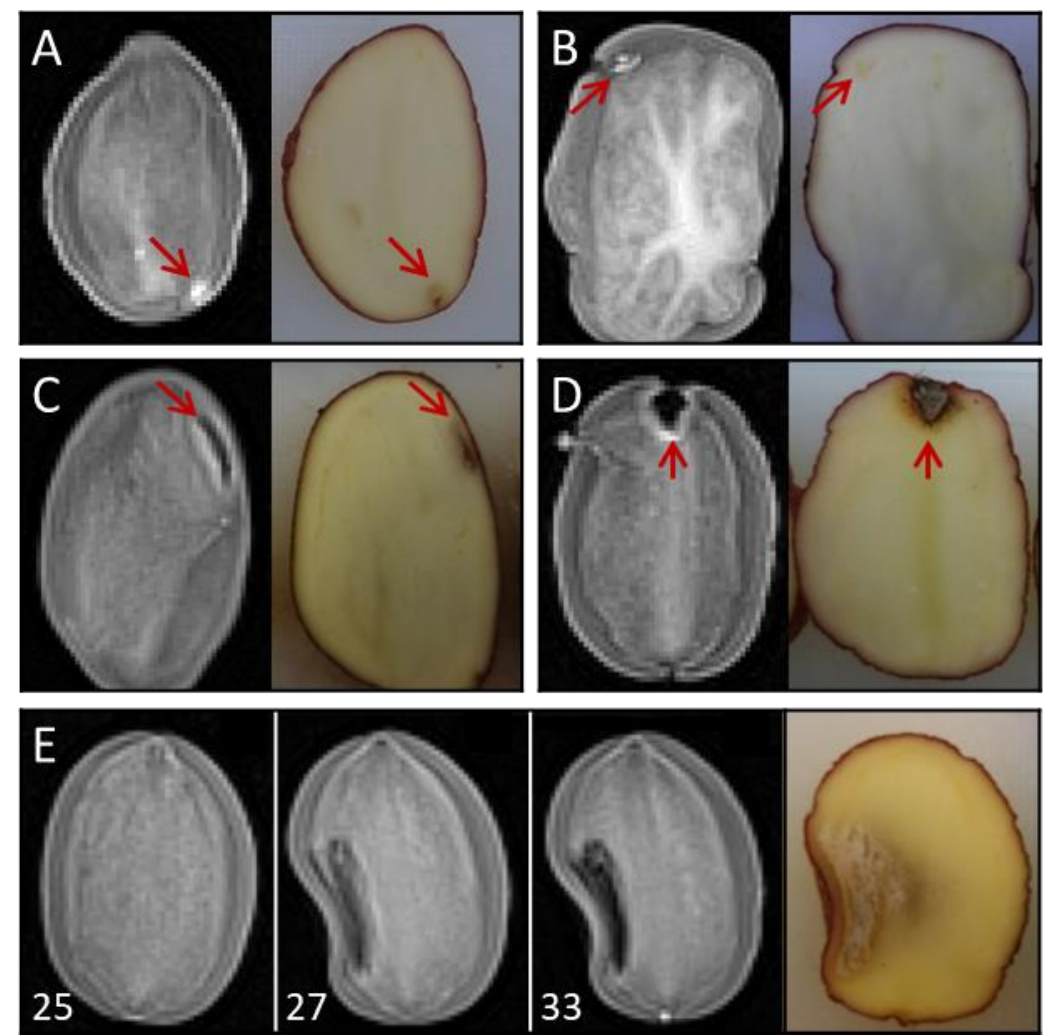

Figure 2: MRI images (left) and photographs (right) of potato tuber slices with defects occurring in peripheral parts of the tissue (cortex). MRI images correspond to 3D fastspin-echo $\mathrm{MRI}$ images (echo time $=28 \mathrm{~ms}$, repetition time $=100 \mathrm{~ms}$, echo train length $=35,0.8 \times 0.8 \times 0.8 \mathrm{~mm}^{3}$ voxel). MRI images $A, B, C \& D$ correspond to measurement session at 33 weeks after harvest (WAH). In (E) numbers represent WAH. 

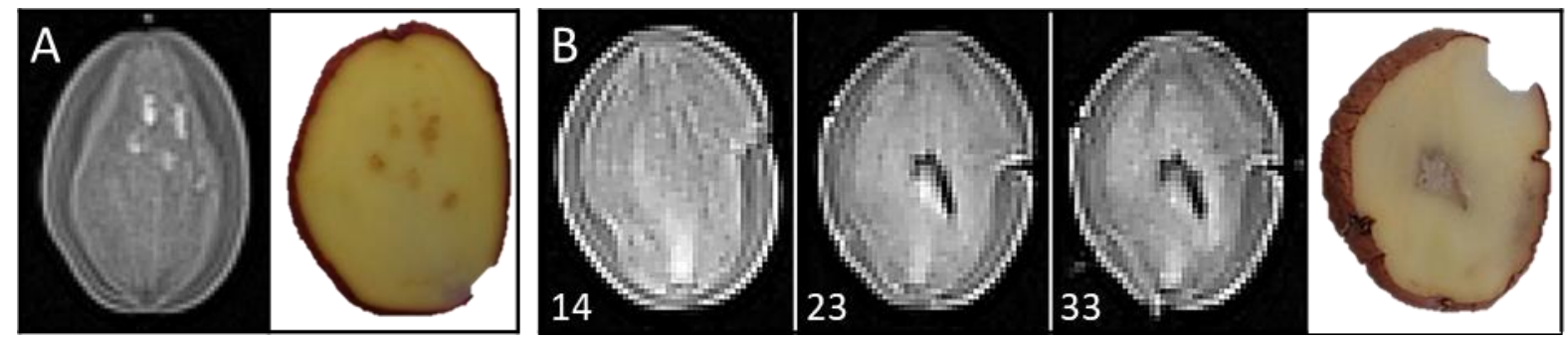

Figure 3: MRI images (left) and photographs (right) of potato tuber slices with defects occurring in central parts of the tissue (perimedullary region or pith). MRI images correspond to 3D fast-spin-echo MRI images (echo time $=28 \mathrm{~ms}$, repetition time $=100$ $\mathrm{ms}$, echo train length $=35,0.8 \times 0.8 \times 0.8 \mathrm{~mm}^{3}$ voxel). In (B) numbers represent weeks after harvest (WAH). 

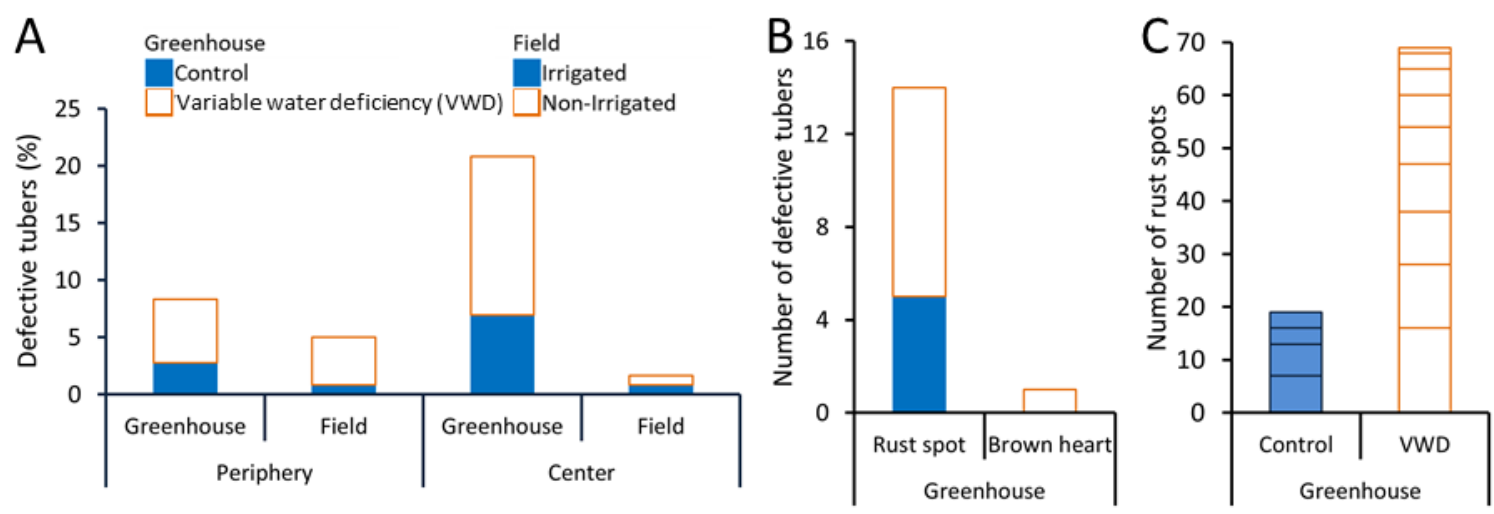

Figure 4: A) Percentage of potato tubers with defects occurring in peripheral (cortex) or central (perimedullary region or pith) tissues from both cultivation conditions (Greenhouse: 72 tubers \& Field: 120 tubers); B) Distribution of defects detected in central tissue; C) Number of rust spots per tuber cultivated in the greenhouse and in the field (each defective tuber is represented by a separate rectangle on the histogram bar). 


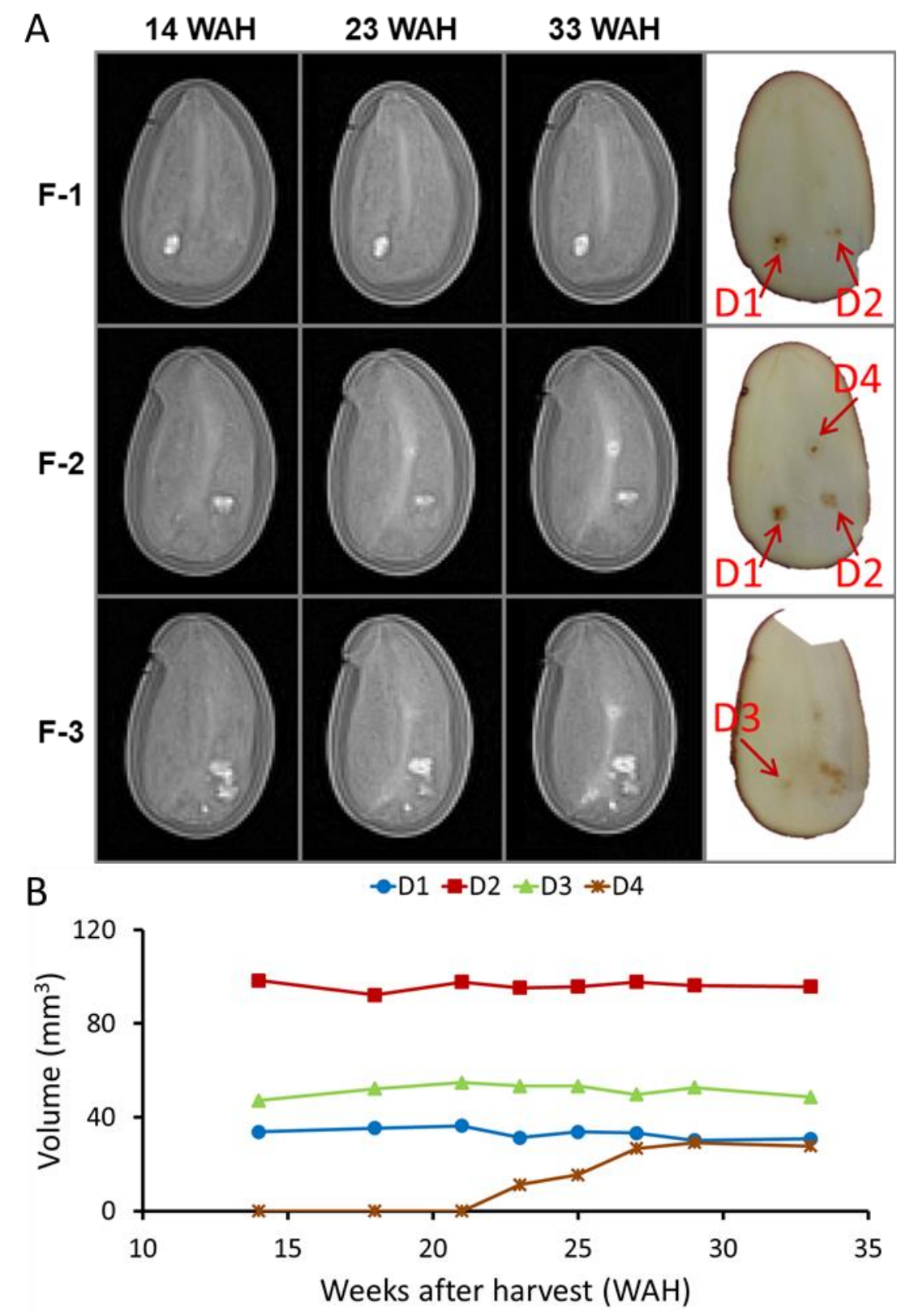

Figure 5: A) 3D fast-spin-echo MRI images (echo time $=28 \mathrm{~ms}$, repetition time $=100$ $\mathrm{ms}$, echo train length $=35,0.8 \times 0.8 \times 0.8 \mathrm{~mm}^{3}$ voxel) of a potato tuber at three different temporal points during storage (columns from left to right: 14, 23, and 33 weeks after harvest WAH). Rows correspond to $0.8 \mathrm{~mm} \mathrm{MRI}$ slices ( $\mathrm{F}-1$ and $\mathrm{F}-2$ are separated by $4.8 \mathrm{~mm}$ and F-2 and F-3 are separated by $1.6 \mathrm{~mm}$ ). Photographs of approximately 2 $\mathrm{mm}$ potato slices of the corresponding tuber are shown in the last column. B) Volume of corresponding rust spots in the course of the storage period expressed as WAH. 

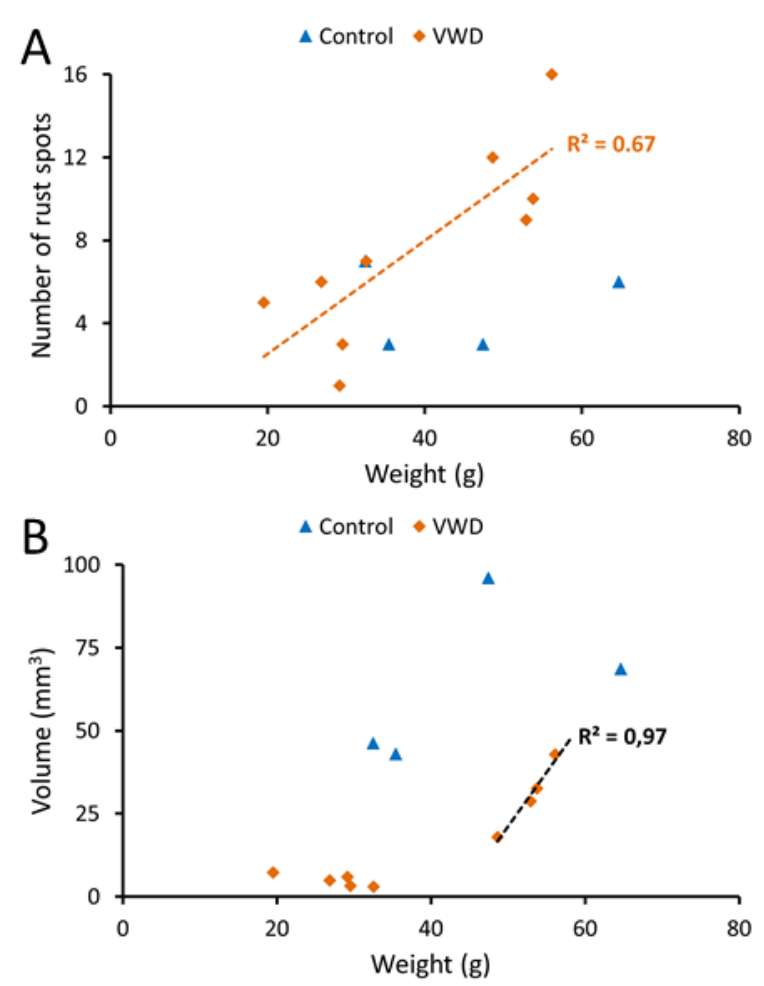

Figure 6: A) Number of internal rust spots per tuber and B) volume of the biggest internal rust spot in each tuber plotted against weight of greenhouse tubers grown under optimal conditions (Control) and under variable water deficiency (VWD). 


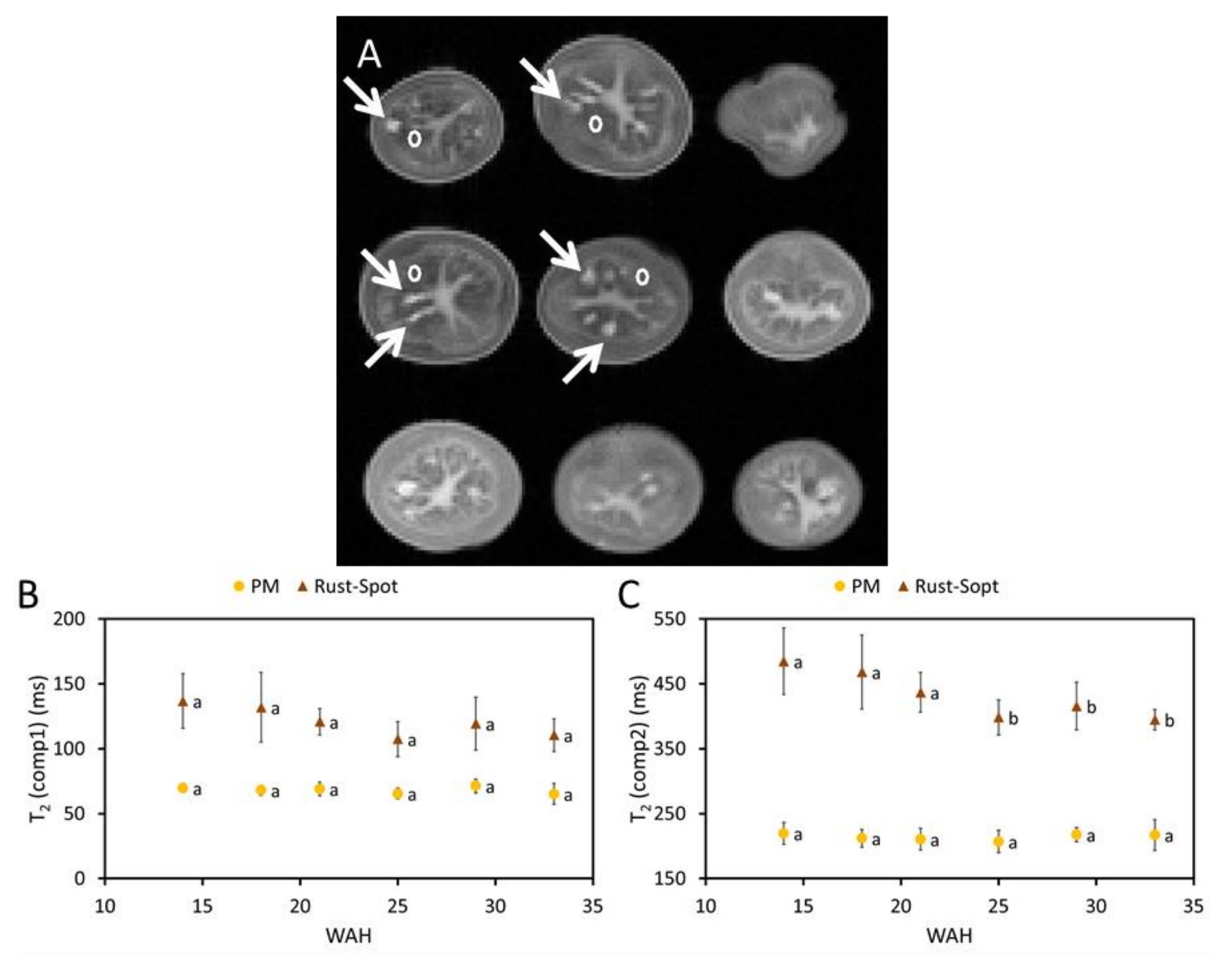

Figure 7: A) Multi-spin-echo MRI image (echo time $=148 \mathrm{~ms}$, repetition time $=10 \mathrm{~s}$, $0.9 \times 0.9 \times 5 \mathrm{~mm}^{3}$ voxel) of a potato tuber with rust spot in the perimedullary region (PM) at 14 weeks after harvest (WAH). Selected rust spots are indicated with arrows and $\mathrm{ROI}$ in $\mathrm{PM}$ are shown with open circles. $\mathrm{B} \& \mathrm{C}$ ) Evolution of mean transverse relaxation times $\left(T_{2}\right)$ of rust spots and neighboring healthy PM during storage expressed as WAH, where different letters correspond to significantly different values (ANOVA, 99\%). 